\title{
Notes on Potential Errors in Estimating Spawning Stock Biomass: Determining the Effects of Non-participatory Adults for Some Groundfish Species
}

\author{
M. P. M. Burton \\ Department of Biology, Memorial University of Newfoundland \\ St. John's, Newfoundland, Canada A1B 3X9
}

\begin{abstract}
Using both old data sets and recent information there are indications that the estimates of spawning stock biomass have been over-optimistic for some commercially important groundfish species. The concept of non-participation had been used for adults, which undergo gametogenesis but fail to spawn successfully, or which have very low participation because fecundity is extremely low for an individual, in comparison to others of the same species. Interannual variability in production of fertilized eggs may also be due to the presence of adults which do not undergo gametogenesis every year and this situation may be much more common than has been previously accepted in setting up stock-recruitment models. Re-calculations of spawning stock biomass for some groundfish species using lower and more realistic participation rates should provide better understanding of stockrecruitment relationships.
\end{abstract}

Key words: biomass, groundfish, maturity, recruitment

\section{Introduction}

Despite a long history of amassing data on spawning potential of commercially important fish species, the basis for data collection has some deep flaws which have affected the proper estimation of spawning stock biomass and stock-recruitment relationships. In order to identify fish which should be included in calculations of spawning stock biomass it is first necessary to know at what point, or by which criteria, a fish can be considered an adult. Usually this partitioning has been achieved by determining a size (length) or age at which $50 \%$ of the population are "mature" (Thompson, 1916; Beacham, 1983), which may give a sharp demarcation. With this information a decision can be made to assign all fish above a certain age or length to spawning stock, which may be subjected to modification with knowledge of ongoing fishing activity (Fukuda, 1962). The spawning stock can be regarded as units of individuals but generally is treated as undivided biomass. Any fluctuation in biomass can be tested for relationships with production of recruits. In such a manner spawning stock biomass/recruitment relationships have been studied for several groups of commercially important fish species and for flatfish such as halibut it has been claimed that there is no stockrecruit relationship (Cushing, 1971) whereas for haddock an inverse relationship has been stated (Ricker, 1954), which was believed to occur because cannibalism of recruits would increase with stock (Beverton and Holt, 1957). Recent reassessments of stock-recruit relationships (Hillborn and Walters, 1992) show some sceptism regarding the prevalence of non-relatedness as stocks decline, with the new view being that recruitment overfishing can be seen to occur with nearly every species studied, except flatfish. Explanation of nonrelatedness, or inverse relationships of stock and recruitment besides cannibalism includes the possibility that recruitment may appear to be independent of stock but that there is an out-ofphase relationship caused by an unspecified environmental factor (Hillborn and Walters, 1992). This paper will suggest means to clarify the unrelatedness of some groundfish stock/recruitment values and the possible environmental situation, which can obscure the relationship. 
A major problem in defining stock and recruitment relationships is the allocation of fish to spawning stock, which can be a more complex matter than previously supposed. Large or old fish do not necessarily participate in reproduction in a regular annual fashion, they may not start or maintain gametogenesis. Even if gametogenesis is maintained there may be individual or group fluctuations in gamete output for either males or females, a possibility which should be factored into stock-recruitment modeling, to give conservative rather than optimistic values for predictions. Moreover, and perhaps the most serious problem for data manipulation, identification of adults and appropriate differentiation of fish which have never reproduced from adults which are not currently reproductive has given considerable confusion in the data-sets. In this paper some of the historical data has been re-evaluated by using recently collected information, and recalculations have been used to see patterns in apparently non-existing or negative stock-recruitment.

\section{Materials and Methods}

Material is derived from historical data sources for halibut Hippoglossus hippoglossus (Thompson, 1916; Kohler, 1967) and Atlantic cod Gadus morhua (Graham, 1924; Anon. 1948; Beacham, 1983).

Failure of an adult to reproduce (nonparticipation) was analyzed on the basis of a) failure to achieve gametogenesis for a particular reproductive season b) failure to complete gametogenesis c) failure to achieve fertilization. Data for these were best for a), rare for $b$ ) and speculative for c). For a) I have been using my own data for two species, Atlantic cod (Gadus morhua) and winter flounder (Pleuronectes americanus), for the latter I have been using previously unpublished data for males and published data for females (Burton, 1991a). Winter flounder were collected by SCUBA divers from specified locations around the Avalon Peninsula, Newfoundland during the winter and immediate prespawning period. They were transported in a tank truck to the Ocean Sciences Centre (Memorial University) where they were either immediately sampled or held for a few days before sampling. Holding tanks were 60 gallon (270 litres) with running degassed seawater at seasonal temperature and photo period. Fish weight and fork lengths were measured. Gonad weight and status were then assessed. Non-reproductive adults were identified by the colour, size and shape of the gonads as follows (see also Burton and Idler, 1987a, b) (note: gonadosomatic index, GSI is gonadal weight $\times 100 /$ body weight):

\section{Males:}

Immature (i.e. never spawned individual)

- very small testes

- GSI <0.2), pink/pale grey

Non-reproductive adult

- medium size testes

- GSI 1.0, grey-brown

Reproductive adult

- large testes

- GSI 3-11, white

Females:

Immature (never spawned)

- small ovaries

- GSI 1.0, pink

Non-reproductive adult

- long flat ovaries

- GSI 2.0 dull red

Reproductive adult

- long rounded ovaries

- GSI 4-15 yellow

Some of the cod data were derived by recalculating from Graham (1924) using his 1922 data and obtaining GSI, where GSI $<1.00$ prespawning was assumed to mean a large female is non-reproductive. The assumption that a low GSI $(<1.00)$ can be taken to equate with the nonreproductive adult status is ultra-conservative compared to values used for winter flounder, see above and Burton and Idler 1984, 1987a,b, and measured in cod (Burton et al., 1997). The comparison with winter flounder is useful and justified in that both species have groupsynchronous oogenesis in a similar cystovarian ovary. Data were also obtained on Barents Sea cod from Shirakova (1969), for Greenland halibut (Reinhardtius hippoglossoides) from Fedorov (1971), for the burbot (Lota lota) from Pulliainen and Korhonen (1990). For b) I used data for $R$. hippoglossoides (Fedorov, 1971). For c) fertilization rates for captive yellowtail Pleuronectes ferrugineus are derived from Manning and Crim (1998). 
Low participation was calculated on the basis of fecundity for determinate spawners winter flounder and Atlantic cod, and fecundity was estimated from GSI for vitellogenic (exogenous, yolky) prespawning fish, excluding any females with hydrated oocytes. The assumption was made that for determinate spawners prespawning the GSI reflects fecundity. The winter flounder used were caught during the winter and sacrificed shortly afterwards (e.g. within a week). The cod data were calculated from Graham (1924) for prespawning North Sea females or from Penney (MS 1994) for prespawning Northwest Atlantic females.

\section{Spawning stock biomass estimates}

Data for two of the flatfish species ("plaice" and "halibut") were used, which are presented for analysis in Fig. 9 of Cushing (1971), confining my analysis for the halibut, to Area 2 (Cushing, 1971). Cushing's data for halibut was of Pacific halibut, i.e. Hippoglossus stenolepis, from the Northeastern Pacific (Fukuda, 1962), using two areas separately; Area 2 (southern grounds) and Area 3 (western grounds). The plaice in Cushing's (1971) Fig. 9 was North Sea plaice, i.e. Pleuronectes platessa (Beverton, 1962). The values were read off for "stock" for both species from Cushing's (1971) Fig. 9. Although Cushing was apparently treating "stock" as equivalent to spawning stock biomass, the equivalence may not be real because "stock" may have included large juveniles or nonparticipatory adults. Therefore, the values were adjusted as shown below.

\section{Stock-recruitment relationships}

Adjusted spawning stock biomass values were substituted into stock-recruit curves for the two flatfish species, halibut (Hippoglossus stenolepis) and North Sea plaice (Pleuronectes platessa), from Cushing (1971). For the substitutions in the halibut curve (Area 2, southern grounds) based on Pacific halibut, Fukuda (1962), the recruitment was arbitrarily divided into three categories, by taking the number of data points and dividing by three, setting the highest 11 points as "high" and so on. The product is: high $(50-100,11$ points $)$, medium (38-50,13 points) and low (18-35, 12 points). The simple prediction was made (discounting any complicating factors for compensation or depensation at extremes of stock) that recruitment would correlate positively with stock when stock was correctly allowed to reflect reproductive participation. Participation rates were set at 50\% (for high recruitment), 20\% (medium) and 10\% (low), which are justified by reference to the apparent participation rates I calculated (see "nonparticipation" calculations for Atlantic halibut in Results below) from Kohler's (1967) data for Atlantic halibut. "Stock" was therefore calculated to give a new value of "spawning stock" based on varying participation rates. Recruitment values were read directly from the original graphs (Cushing, 1971), except that two data points for the highest recruitment values were beyond the highest value accurately given on the log scale and were therefore treated equally with the highest value. The data (Fukuda, 1962) which Cushing (1971) used is available for years 1911-55, with two alternate sets of values for residual stock and Fukuda's units as millions of pounds. The plot for plaice (Pleuronectes platessa) was treated similarly to the halibut but all recruitment values were read from the scale. Cushing derived the values from Beverton (1962), in which the data were given only in graph format (no units provided) for unspecified years including the 1930s up to at least 1949 .

\section{Results}

\section{Maturity estimates in the past}

Thompson (1916) who studied Pacific halibut, was unable to access fish throughout the expected spawning season, but obtained sufficient mature/ spent females to provide graphs of age and length at maturity: the plot for age at maturity shows that although mature fish are recorded at age VII, 50\% maturity is not seen until age XII, and this stagger continues, with age XV still only showing $90 \%$ maturity. The $100 \%$ maturity level is not reached until age XVII, by which age few fish are present; from one area (Frederick Island) of three studied, no females above age XIII are recorded, and off Kodiak Island the oldest females are age XVIII.

Kohler (1967) provides tables of Atlantic halibut (males $n=310$, females $n=292$ ) classified as immature, ripe-running or spent-recovering for spring and for late summer/autumn. It was clear that the term "immature" was used uncritically as it includes large fish, for both males and females. The size range for "immature" fish for both sexes was $16-110 \mathrm{~cm}$ with very few fish of either sex (2 males and 9 females) in the larger size classes. Few fish (30 males and 18 females) were actually classified as reproductive i.e. ripe-running or spentrecovering. Even in the size range $>91 \mathrm{~cm}$ length 
$25 \%$ of the males (5 fish) were still classified as immature, while 50\% (13 fish) of this size-class of females were also classed as immature even though the smallest reproductive fish (male and female) were in the $41-50 \mathrm{~cm}$ size-class. I assume therefore that this author could not differentiate nonreproductive adults from juveniles, which had never spawned.

Atlantic cod records (Anon., 1948) show that there had been considerable uncertainty about maturity stages in the past for this fish. Large fish originally classed as immature have been subsequently reclassified (Fig. 1), but it is not clear whether this was done on any other basis than large size.

Graham (1924) studied North Sea cod, and the records show uncertainty about allocation of fish to classes for reproduction. Graham mentions barren cod, but he does not quantify them, nor even explain his reason for knowing or suspecting their existence. Graham also states that "it is impossible in practice to distinguish small spent fish, either male or female, from immature fish." In an extensive analysis of male and female cod obtained in January and March 1923, Graham (1924) lists 499 mature males and 155 immature males, with 324 mature females and 164 immature females. Within the immature classification he includes females up to $97 \mathrm{~cm}$ long and males up to $89 \mathrm{~cm}$ long.

Beacham (1983) shows maturity ogives (length versus \% mature) for Scotian Shelf Atlantic cod (Subdiv. 4Vs); in 1959-64 for both males and females, large fish were not necessarily $100 \%$ "mature", of 11 data points for males of length $\geq 70$ $\mathrm{cm}$ only three showed $100 \%$ maturity, the rest showed $75-95 \%$ maturity. For females of length $\geq 70$ $\mathrm{cm}$ in the same time frame 12 data points showed six at $100 \%$ maturity with the remainder at $85-95 \%$ maturity. However, as the time series progressed, more large fish data points were at the $100 \%$ level and by 1975-79 there were no outliers for fish $>70$ $\mathrm{cm}$; all data points were on the $100 \%$ level. Similar trends were seen for Subdiv. $4 \mathrm{Vn}$ and Div. $4 \mathrm{~W}$ but Div. $4 \mathrm{X}$ retained some "immature" fish in the large size-classes up to 1979.

\section{Non-participation}

a) Failure to achieve gametogenesis for a particular reproductive season

Winter flounder (Pleuronectes americanus). Non-reproductive winter flounder, from wild populations calculated for three consecutive years showed values from 10-30\% for females (Burton, 1991a) and 5-35\% for males.

Greenland halibut (Reinhardtius hippoglossoides). Fedorov (1971) showed 9.5\% nonbreeding females and $2.8 \%$ sterile fish.

Cod (Gadus morhua). For North Sea cod, Graham (1924) showed prespawning females ( $n$ $=54)$ in 1922 in the size range $>50 \mathrm{~cm}, 59 \%$ were non-reproductive. Shirakova's (1969) data for young cod showed 99\% spawning for 5year-old females in 1961, with a drop to $89 \%$ spawning for the same cohort the next year. Likewise the 1957 male cohort attained 99\% spawning in 1961, which dropped successively to $94 \%$ spawning in 1962 and $92 \%$ spawning in 1963.

Halibut (Hippoglossus hippoglossus). From Kohler's (1967) data for Atlantic halibut it seems clear that a lot of the fish listed as immature in the higher size-range were actually non-reproductive adults. For the total 239 females $>41 \mathrm{~cm}$, a size at which reproduction can occur, there were only $7.53 \%$ reproductive fish. At the greater size of $>61 \mathrm{~cm}(n=120)$ only $14.17 \%$ females were reproductive. For the largest females $>91 \mathrm{~cm}(n=26)$ only $50 \%$ were actively reproductive. To achieve the $100 \%$ reproduction level for females it is necessary to exclude all but the very large fish $(>111 \mathrm{~cm}$, $n=9$ ).

Burbot (Lota lota). Pulliainen and Korhonen (1990) found that the gadid burbot from the northern most Baltic area off Finland can have a high level of non-maturing fish in the large size-classes. Both males and females were capable of reproduction at size-classes 32-30 $\mathrm{cm}$, but even at sizes $>50 \mathrm{~cm} 30 \%$ females and $13 \%$ males were non-maturing. 


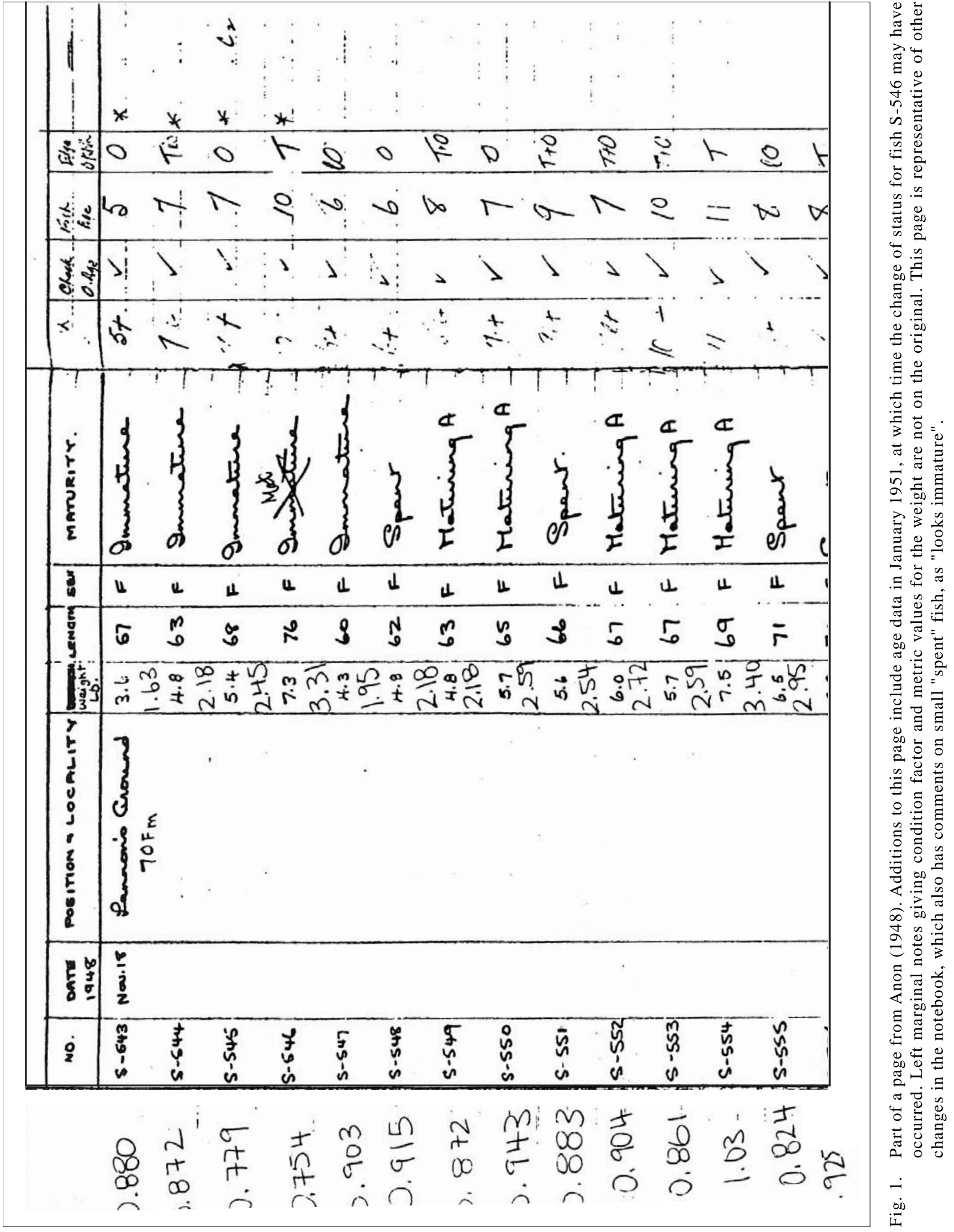


b) Failure to complete gametogenesis

Fedorov (1971) records mass gamete resorption by Greenland halibut females (Reinhardtius hippoglossoides) in response to temperature anomalies; but this situation is reported for a summer spawning period auxiliary to the main winter spawn. It is not clear whether Fedorov believed some fish to have two spawnings per year but he does state that "once a fish has undergone a mass resorption it may subsequently miss one or more subsequent annual spawnings". His data show $8.3 \%$ females "missing the summer spawn" by re-sorption.

\section{c) Failure to achieve fertilization}

For captive $P$. ferrugineus individual mean (for batches) fertilization rates can vary from $87 \%$ to 5\% (Manning and Crim, 1998), with two individuals $<10 \%$. Individual batches could show $0 \%$ fertilization, with huge variation for any individual female; one fish with 17 batches had from $0-87 \%$ fertilization and another with 16 batches had $1-32 \%$ fertilization. For two consecutive years $(n=11,10)$ the mean fertilization was $38 \%$ and $57 \%$.

\section{Low participation}

The winter flounder GSI for reproductive females shows some individual variation in the prespawning season, in four different years $(n=15$, $14,10,15)$ the mean and range were $14.24(9.8-$ 20.09), 13.56 (7.83-23.57), $11.89(6.5-22.8)$ and 13.24 (9.35-18.15). The cod GSI shows considerable variation in prespawning; for North Sea females (1922), $n=21$, the mean was 5.32 , with a range of 1.54-11.81. For cod off Newfoundland (February, 1992), $n=9$, the mean was 5.92 with a range of 2.5-10.12.

\section{Spawning stock biomass estimates}

Starting with usual estimates of spawning stock biomass, the values can be modified by applying estimates of non-participatory adults, and perhaps also effects of low participation. For Pacific halibut where spawning stock is apparently taken (Fukuda, 1962) to include even influxes of young fish ("chickens", 7 year-olds) it is reasonable to apply corrections to the data. For Fukuda, stock is implied to be equal to spawning stock but he calculates residual stock from landed fish including small- sizes, but does not give any values for lengths of fish caught. Inspecting available length and age data for Pacific halibut, Thompson's (1916) data from the North Pacific show high variation for lengthat-age. Converting Thompson's data from inches to $\mathrm{cm}$ for three locations, seven year-old fish were 61 $\mathrm{cm}, 66 \mathrm{~cm}$ or $81 \mathrm{~cm}$ in length. Applying this to Kohler's (1971) data, for females $>61 \mathrm{~cm} 14.5 \%$ would be reproductive; the data cannot discriminate for the $>66 \mathrm{~cm}$ level, but for the $>81 \mathrm{~cm}$ size $39 \%$ would be reproductive. Given some variation in size distribution and mean fecundity interannually it is proposed that in any given year a correction of from $10 \%$ to $50 \%$ of total stock could represent the real spawning stock participating in reproduction for halibut.

\section{Stock-recruitment relationships}

The stock recruitment plot from Cushing (1971) and for Area 2 Pacific halibut from Fukuda (1962) showed no clear evidence of a positive relationship between stock and recruitment, supporting in Cushing's view the idea that recruitment was independent of stock, over "the range of fishable stock". By re-analyzing the stock values, and by restricting the stock to likely reproductive fish as opposed to the entire stock fished (Fig. 2), the new

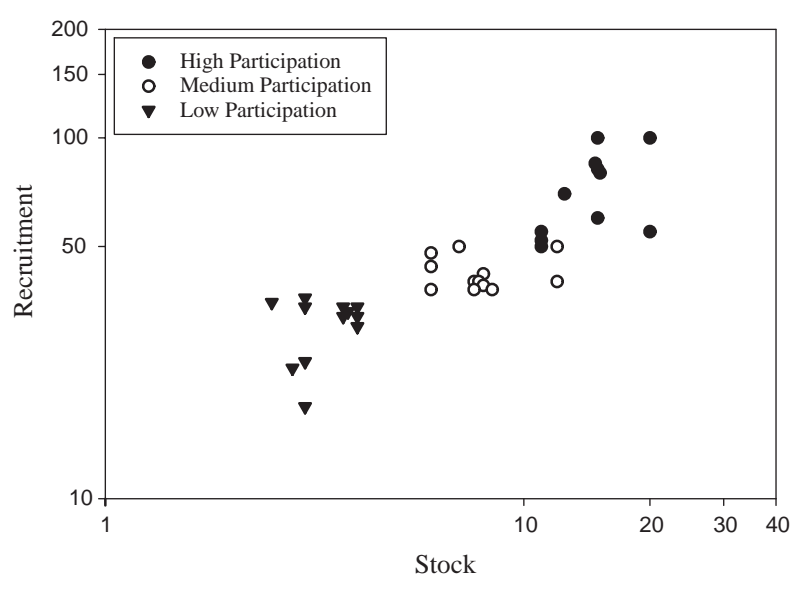

Fig. 2. Pacific halibut (Hippoglossus stenolepis) stock recruitment relationship (in logs) from Cushing (1971) after Fukuda (1962), recalculated with varying participation rates $(50 \%, 20 \%, 10 \%)$ based on levels of recruitment (high, medium, low), obtained arbitrarily. The two highest recruitment data points were difficult to read on the original plot ( $>100$ on a log graph, with a scale terminating at 100) and were therefore rendered as 100 . 
plot changes drastically in comparison to the original. The new plot (Fig. 2) shows a possible dependency of recruitment on stock when "stock" is spawning stock biomass as calculated from fished stock; the correlation is positive $r=0.844, p=$ $<0.001$. A similar but weaker relationship is found for North sea plaice if the same adjustment is made for stock, from stock (fishable) to spawning stock biomass (Fig. 3). The original graph in Cushing (1971), based on Beverton's (1962) data supports Beverton's conclusion that recruitment was independent of stock "over the range of stock fished." When, however, the stock value is recalculated (as for Fig. 2) to give stock as "spawning stock biomass" based on possible participation rates then there is a positive correlation between recruitment and stock, at $r=$ $0.407, p=0.1-0.05$.

\section{Discussion}

Recruitment variability may be dependent on many other factors such as food and predation directly affecting larval and juvenile survival rather than variability in stock, as indicated by Miller et al., (1991). However analysis of stock relative to spawners in the stock may help understand why some stock-recruit relationships have been so difficult to clarify. Flatfish species have been central to the idea (or "dogma" (Cushing, 1971)) that recruitment can be independent of stock; and Cushing himself when analyzing available data was

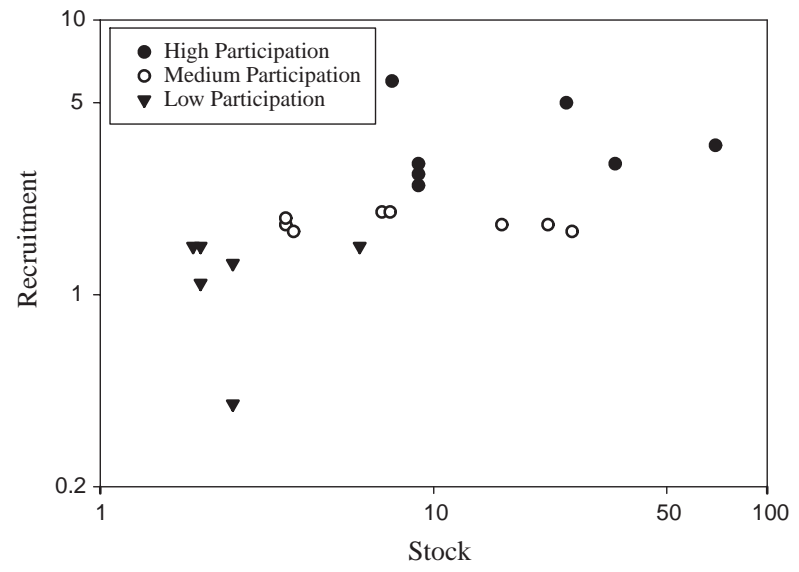

Fig. 3. North Sea plaice (Pleuronectes platessa) stock recruitment relationship (in logs) from Cushing (1971) after Beverton (1962), recalculated with varying participation rates, as for Pacific halibut. unable to show dependence for such species even though it could be demonstrated for other groups of teleosts. Particularly clear stock-recruitment dependence was seen in plots obtained for anadromous salmonids (Cushing, 1971), which is interesting because the stock analyzed had only been of migrating fish, and therefore reproductive fish. Stock analysis for groundfish, however, has been based on landings, the values of which may then be used to calculate residual stock (Fukuda, 1962), but which do not allow for the fact that not all fish in a stock are actively or maximally reproductive in any one year.

The recalculation of two of Cushing's flatfish stock-recruitment graphs was performed to test whether the concept of varying participation rates could show order in the apparently independent relationship. By substituting new values for spawning stock into the old stock values a dependent relationship could be obtained, particularly in the case of halibut. The substitution had been obtained by using participation rates based on Atlantic halibut (re calculations based on Kohler's 1967 data) and applying them to Pacific halibut. Also halibut may be an extreme case of "non-participation" and it may have been rash to apply halibut participation rates to plaice. Unfortunately there is almost no data on "nonparticipation" for Pleuronectes platessa. Rijnsdorp (1990) found high levels $(\sim 50 \%)$ of females which did not reproduce in a laboratory experiment, but he thought that such reproductive omission was not found in wild fish. However, one of his graphs of wild fish showed "spent" fish at times which would indicate spawning omission, especially shortly before the spawning season. Work on the closely related winter flounder (Pleuronectes americanus) has consistently shown that it is subject to spawning omission, after experimental food deprivation (Tyler and Dunn, 1976; Burton and Idler, 1991b) and in the wild (Burton and Idler, 1984; Burton, 1991a). However winter flounder might be regarded as a special case because it undergoes an extensive winter fast in the northern part of its distribution range.

In a review (Bull and Shine, 1979) of iteroparous (repeat reproducing) animals which may "skip reproduction", only six species of fish were listed, in comparison to 27 amphibia and 18 reptiles. The fish species did not include any fully marine teleosts, but we now know that reproductive 
omission can be found in several Northern pleuronectids and in gadids. Recent papers have also shown that reproductive omission occurs in a Southern gadoid Macruronus novaezelandiae (Livingston et al., 1997); for females reproductive participation varied interannually from $67 \%$ to $82 \%$. Another southern fish, the commercially important orange roughy (Hoplostethus atlanticus) also shows spawning omission (Bell et al., 1992), with an estimate of $45 \%$ non-reproductive females for 1990 .

Although Pulliainen and Korhonen (1990) believe that for burbot (Lota lota) spawning omission is not nutrition related, their data are based on current conditions rather than the conditions which might have evoked spawning omission. In general it is possible to relate spawning omission to varying food supplies, and experimentally it is possible to evoke or reverse the non-reproductive state in winter flounder (Burton, 1991b, 1994). Given that varying nutrition will also affect fecundity, there is the possibility that it is feeding success that drives the stock-recruitment relationship from the stock side. In the case of Northwest Atlantic cod, lack of capelin (Mallotus villosus) at critical points in the reproductive cycle may affect both fecundity and participation of males and females.

\section{Acknowledgements}

Barbara Neis gave me a copy of the cod notebook (Anon., 1948). Rick Rideout produced the graphs and Chris Burton translated the Russian text.

\section{References}

ANON. 1948 Cod age notebook 1947-48 Book 2. Department of Fisheries and Oceans, St. John's, Newfoundland, Canada.

BEACHAM, T. D. 1983 Variability in median size and age at sexual maturity of Atlantic cod, Gadus morhua, on the Scotian shelf in the Northwest Atlantic ocean. Fish. Bull., 81: 303-321.

BELL, J. D. LYLE, J. M., BULMAN, C. M., GRAHAM, K. J., NEWTON, G. M., and D. C. SMITH. 1992. Spatial variation in reproduction, and occurrence of non-reproductive adults, in orange roughy, Hoplostethus atlanticus Collet (Trachichthyidae), from south-eastern Australia . J. Fish Biol., 40: 107-122.

BEVERTON, R. J. H. 1962. Long-term dynamics of certain Noth Sea fish populations. In: The exploitation of natural animal populations. Le Cren and Holdgate (eds.), Oxford, Blackwell, p. 242-264.
BEVERTON, R. J. H., and S. J. HOLT. 1957. On the dynamics of exploited fish populations. Fish. Invest., Lond., Ser.2, 19: 533 p.

BULL, J. J., and R. SHINE. 1979. Iteroparous animals that skip opportunities for reproduction. Am. Nat., 114: 296-303.

BURTON, M. P. M. 1991a. A physiological basis for nonannual spawning in winter flounder. Proc. 4th Int. Symp. Reprod. Physiol. Fish, 164 p.

$1991 \mathrm{~b}$. Induction and reversal of the nonreproductive state in winter flounder, Pseudopleuronectes americanus Walbaum, by manipulating food availability. J. Fish Biol., 39: 909-910.

1994. A critical period for nutritional control of early gametogenesis in female winter flounder Pleuronectes americanus. J. Zool. Lond., 233: 405415.

BURTON, M. P. M., and D. R. IDLER. 1984. The reproductive cycle in winter flounder, Pseudopleuronectes americanus (Walbaum). Can. J. Zool., 62: 2563-2567.

1987a An experimental investigation of the nonreproductive, post-mature state in winter flounder. J. Fish Biol., 30: 643-650.

1987b. Variability of reproductive status in a population of Pseudopleuronectes americanus. Prov.V Congr. europ. Ichthyol., Stockholm 1985, p. 207-212.

BURTON, M. P. M., R M. PENNEY, S. BIDDISCOMBE. 1997. The time course of gametogenesis in Northwest Atlantic cod (Gadus morhua L.). Can. J. Fish. Aquat. Sci., 54(Suppl.1): 122-131.

CUSHING, D. H. 1971. The dependence of recruitment on parent stock in different groups of fishes. ICES J. Cons., 33: 340-362.

FEDOROV, K. Y. 1971. The state of the gonads of the Barents Sea Greenland halibut [Reinhardtius hippoglossoides (Walb)] in connection with failure to spawn. J. Ichthyol., 11: 673-682.

FUKUDA, Y. 1962. On the stocks of halibut and their fisheries in the Northeastern Pacific. Int. North Pac. Fish Comm. Bull., 7: 39-50.

GRAHAM, M. 1924. The annual cycle in the life of the mature cod in the North Sea. Fish. Invest., Ser. 2, 6(6): $77 \mathrm{p}$.

HILLBORN, R., and C. J. WALTERS. 1992. Quantitative fisheries stock assessment, choice, dynamics and uncertainty. Chapman and Hall, New York.

KOHLER, A. C. 1967. Size at maturity, spawning season, and food of Atlantic halibut. J. Fish. Res. Board Can., 24: 53-66.

LiVInGSTON, M. E., M. VignAUX, and K. A. SCHOFIELD. 1997. Estimating the annual proportion of nonspawning adults in New Zealand hoki, Macruronus novaezelandiae. Fish.Bull., 95: 99-113.

MANNING, A. J., and L. W. CRIM. 1998. Maternal and inter-annual comparison of the ovulatory periodicity, egg production and egg quality of the batch-spawning 
yellowtail flounder. J. Fish Biol., 53: 954-972.

MILLER, J. M., J. S. BURKE, and G. R. FITZHUGH. 1991. Early life history patterns of Atlantic North American flatfish: likely (and unlikely) factors controlling recruitment. Neth. J. Sea Res., 27: 261275.

PENNEY, R. M. MS 1994. A study of oogenesis in Atlantic cod (Gadus morhua L.) from NAFO Divisions 2J3KL with evidence for a possible adolescence stage. Hons. thesis, Memorial Univ., Newfoundland, Canada.

PULLIAINEN, E., and K. KORHONEN. 1990. Seasonal changes in condition indices in adult mature and non-maturing burbot, Lota lota (L.), in the northeastern Bothnian Bay, northern Finland. J. Fish Biol., 36: 251-259.

RICKER, W. E. 1954. Stock and recruitment J. Fish. Res. Board Can., 11: 152-216.

RIJNSDORP, A. D. 1990. The mechanism of energy allocation over reproduction and somatic growth in female North sea plaice, Pleuronectes platessa L. Neth. J. Sea Res., 25: 279-290.

SHIRAKOVA, M. Ya. 1969. The sexual maturation rate of the generations of Baltic cod taken from 196163. Atlanticheskii Nauchno-Issledovatel'skii Institut Rybnogo Khoziaistva i Okeanografii. Trudy. Kaliningrad, 21: 37-44. In Russian.

THOMPSON, W. F. 1916. The problem of the halibut. Prov.of British Columbia Report of the Commissioner of Fisheries for the year ending 1915. S130S140.

TYLER, A. V., and R. S. DUNN. 1976. Ration, growth, and measures of somatic and organ condition in relation to meal frequency in winter flounder Pseudopleuronectes americanus, with hypotheses regarding population homeostasis. J. Fish. Res. Board Can., 33: 63-75. 
